\title{
Analyzing EFL Teachers' Initial Job Motivation and Factors Effecting Their Motivation in Fezalar Educational Institutions in Iraq
}

\author{
Selcuk Koran \\ Preparatory School, Ishik University, Erbil, Iraq \\ E-mail: selcuk.koran@ishik.edu.iq
}

Doi:10.7575/aiac.alls.v.6n.1p.72

Received: 18/09/2014

URL: http://dx.doi.org/10.7575/aiac.alls.v.6n.1p.72

Accepted: 21/11/2014

\begin{abstract}
Teacher motivation is one of the primary variables of students' high performance. It is experienced that students whose teachers are highly motivated are more engaged in the learning process. Therefore, it's mostly the teacher who determines the level of success or failure in achieving institution's goal in the educational process. Thus, teachers are expected to demonstrate a high job motivation performance by administrations. However, some teachers seem naturally enthusiastic about teaching while others need to be stimulated, inspired and challenged. There are several factors that provide teachers with necessary motivation driven by which they can work effectively. These factors can be emotional, financial, physical or academic. This study is an attempt to find out what motivates teachers to enter this profession, since the reasons of entering this job has significant influence on their commitment to the job, investigate factors which are responsible for high or low motivation of language teachers in Fezalar Educational Institutions (FEI), which is a Turkish private institution that operates in Iraq, and ascertain the degree to which intrinsic and extrinsic motivational factors impact teachers in their work situation. Based on the review of the recent researches of motivation, in general, and of language teacher motivation, in particular, and relying on the qualitative and quantitative study of the issue, a detailed analysis of some aspects of foreign language teacher motivation is presented in the article.
\end{abstract}

Keywords: teacher motivation, job satisfaction, foreign language teaching, L2 teacher motivation

\section{Introduction}

Human resources are the most significant and the most expensive value for any organization. As for the educational organization, teacher's role is vital to the success of the most educational institution. It's mostly the teacher who determines the level of success or failure in achieving institution's goal in the educational process. It's the teacher who gives the institution its credibility and determines its character (Wicke, 1964). The teacher is considered to be a vehicle that presents subjects to the students and helshe has the greatest impact on the lives of the students. Moreover, the teacher is a major role model in the lives of the students who idealize them and through whom they develop their worldview.

Teachers are expected to demonstrate a high job performance by administrations. Thus, it is challenging to be a teacher in any school or university nowadays! Even the best teachers reach moments of frustration or burnout. Perhaps as a result of these circumstances many good teachers leave teaching in the first three years (Frase 1992). Obviously, administrators must find ways to keep teachers in the profession and keep them motivated.

Some teachers seem naturally enthusiastic about teaching while others need to be stimulated, inspired and challenged. Many educational institutions organize different kinds of social and academic events to motivate teachers and encourage them to become self-motivated. There are several factors that provide teachers with necessary motivation driven by which they can work effectively. Those factors can be emotional, financial, physical or academic. Many educators are unanimous that teachers are primarily motivated intrinsically by a sense of accomplishment, self-respect and responsibility. However, for maintaining teachers' enthusiasm extrinsic factors should also be taken into account by the administrations. This study is an attempt to find out factors which are responsible for high or low motivation of language teachers in Fezalar Educational Institution (FEI), which is a Turkish private institution that operates in Iraq, and ascertain the degree to which intrinsic and extrinsic motivational factors impact teachers in their work situation. The main objective of this paper is to identify the motivating and demotivating factors and thus suggest possible recommendations to all persons interested to help improve the motivational level of teachers in FEI.

This study aims to investigate two research questions:

1. The reason that motivated EFL teachers to enter this job;

2. To find out to which level they are motivated and investigate motivating factors.

The study is highly significant of its kind since it may help administrative bodies, principals, educators and parents plan how to work for the improvement of teacher motivation by enhancing the positive factors found in this study. 


\section{Theoretical Perspectives And Literature Review}

\subsection{Definition and Theories of Motivation}

Scholars have approached the concept of motivation from different perspectives. The term motivation is complex and difficult to define; therefore a precise definition of this concept is elusive as the notion comprises the characteristics of an individual and a situation as well as the perception of that situation by an individual (Ifinedo 2005, Rosenfield and Wilson 1999). Golombiewski (1973, p.597) discusses motivation as the degree of readiness of an organization to pursue some designated goal and implies the determination of the nature and locus of forces inducing the degree of readiness. To Gibson, Ivancevich and Donnelly (2000) motivation is a word used to describe forces acting on or within a person to initiate and guide behavior. Dessler, (2001) defines motivation as the intensity of the person's desire to engage in some activity. Harmer (2001:51) refers to motivation as "some kind of internal drive which pushes someone to do things in order to achieve something". From the definitions above, it can be summarized that motivation is something that starts, moves, directs, energizes and maintains human behavior. A motivated employee is easy to spot by his/her agility, dedication, enthusiasm, focus, zeal and general performance and contribution to organizational objectives and goals (Ifinedo, 2003).

To Williams and Burden (1997:111) "interest, curiosity, or a desire to achieve" are the key factors that compose motivated people. However, they believe that arousing interest is not enough to be motivated. This interest should be nourished. A highly motivated person will work hard to achieve the performance goal; on the other hand, an unmotivated person will not work so hard which will in turn cause low productivity. Schultz, Sono and Werner (2001) point out that motivation is intentional as well as directional. A motivated person always knows that a specific goal must be achieved and helshe uses most of his her energy and effort to achieve this goal even in most difficult times.

Abraham Maslow's theory of hierarchy of needs (1943) is one of the mostly recognized motivation theories. According to Maslow there are five basic needs of each individual: physiological needs which include pay, food, shelter, etc., security needs which include job security, protection against threats, safety, etc. affiliation needs which include the need of love and affection, esteem needs include the needs for respect, autonomy, achievement, recognition, etc.; self actualization needs include realizing one's full potential and ability. According to Maslow, once a person's need is satisfied it is no longer a need, so the need at the next level of the hierarchy motivates employees. Many empirical studies have supported the motivational force of physiological, safety, love and esteem needs; however, the same studies failed to discover hierarchical arrangement. There is some evidence that opposes the order of needs in Maslow's model. For example, in one culture some people might place social needs before any others. Despite the lack of scientific support, this theory is very well-known since it's the first theory of motivation.

According to Johnson (1986), there are three theories of motivation and productivity that employees' motivation is based on: Expectancy theory- Individuals are more likely to try in their work if they expect a reward worth working for, such as a bonus or a promotion, than if there is none. Equity theory-Individuals are dissatisfied if they are unfairly treated for their efforts and accomplishments. Job enrichment theory- When the work is varied and challenging, employees become more productive. The first two theories represent extrinsic factors which offer a financial reward for a teacher who achieves the preordained goals. This indicates a link between the effort and reward. People are thought to be more motivated if their effort is rewarded and they are not productive if their efforts are not equally compensated. Consequently, equity and fairness at work lead to job satisfaction and high motivation. Educational administrators should consider these theories which link teachers' needs satisfaction and job performance and they should make sure that teachers should be rewarded, fairly paid and professionally challenged.

However, Odden and Kelley (1997) having reviewed the recent research and experience and concluded that individual merit and incentive pay programs do not work and, in fact, are often detrimental. Many studies indicated that merit pay might not be appropriate to organizations such as schools which need cooparative and collabrative work (Lawler, 1983). On the other hand, merit pay system or performance-based system can be productive mostly in business community.

There are primarily two types of motivation: extrinsic motivation and intrinsic motivation (Herzberg 1959)

\subsubsection{Extrinsic motivation}

Extrinsic factors are related to the context or environment in which the job is performed (Herzberg, Mausner and Snyderman, 1959). Extrinsic motivation occurs as a result of external environment, external to a job and it is usually created by others. Extrinsic motivation is not related to the task which is performed by people. Teachers can be motivated extrinsically by means of salary, bonus, pension, insurance, promotion, days-off, praise, etc., all of which might contribute to motivation to teach and job satisfaction as well. An example of this would be a school administrator rewarding a teacher whose students achieve the highest score in the national test.

\subsubsection{Intrinsic motivation}

Intrinsic motivation stems from the internal factors and it is generated by the doer him/herself. Certain behavior is performed by a person because it gives him lher pleasure and a person gets a psychological reward rather than physical. Ellis (1984) discusses that "teachers are primarily motivated by intrinsic rewards such as self-respect, responsibility, and a sense of accomplishment." To Frase (1992), teachers choose to become teachers to help young people to learn and their most gratifying reward is accomplishing this goal. An example of this would be a teacher whose students successfully graduate from the college. This teacher gets the sole satisfaction as helshe sees his $\backslash$ her students at the graduation ceremony in their graduation gowns. 


\subsection{Teacher Motivation}

After doing something for a while, our curiosity gradually fades. Some of us lose the enthusiasm and pleasure about the work we do; some of us continue to preserve the long term benefits. Others try to change the job in order to get back their enthusiasm. This scenario is known by many organizations and educational institutions. Some teachers might be highly motivated, others not. This issue is one of the primary challenges for many school administrators because teacher motivation determines the level of success or failure in achieving an institution's goal in the educational process.

Since researchers thought that language success was connected mostly with students' motivation, there were not many studies conducted on teacher motivation in the past. However, since the 1990s researchers started to investigate teacher motivation as they had realized that teacher motivation had a great impact on student motivation. Pennington seems to be the pioneer of this kind of research with her articles related to teacher motivation in 1991, 1992. In her articles she writes about ESL teachers' work satisfaction and dissatisfaction and the role of teachers' motivation to improve their performance. Another significant figure on teacher motivation is Dörney. In 2001 he mentioned the importance of teacher motivation by stating "The teachers' level of enthusiasm and commitment is one of the most important factors that affects the learners' motivation to learn" (p. 156).

Pennington (1995) states that to improve teacher motivation employers need to address and eliminate de-motivating factors in their teaching environment. Those factors can be stress, heavy workloads, work hours, job stability, disagreement with teaching methods, etc. Teacher motivation and classroom efficacy can be increased if those factors mentioned above are removed from the work environment. Doyle and Kim (1999) listed factors that cause dissatisfaction among ESL and EFL teacher:

- "Lack of respect from administration

- Lack of advancement opportunities

- Lack of long term employment and job security

- Overly heavy work loads

- Separation and alienation of teachers

- Lack of rewards for creativity

- The malfunctioning of the educational system

- Lack of funding for projects

- Lack of autonomy in the teaching and evaluation

- Lack of appropriate teaching environment

- Over-commercializing textbooks

- Discrepancies in teaching philosophies

- Lack of teacher training

- Institution of team teaching and foreign assistant teacher"

Teachers who work in these conditions will lose their motivation which will in turn create less effective learning environment. Most teachers consider these factors as an important barrier which hinders effective teaching. Many teachers even quit their profession as a result of one or some of those factors listed above.

Both extrinsic and intrinsic motives do motivate everyone not just teachers. Promotion opportunities, good working conditions, job security, etc. are external factors which increase teacher motivation. However, some studies reveal that students who were taught by an extrinsically motivated teacher demonstrated lower engagement in tasks and lower interests in learning; on the other hand, students who were taught by an intrinsically motivated teacher showed a great interest and engagement in the learning process. Sergiovanni (1967) found that teachers obtain their greatest satisfaction not through external factors but through a sense of achievement in reaching and affecting students, experiencing recognition, and feeling responsible. Wild T. C., Enzle M. E. and Hawkins W. L. (1992) found that teachers who were perceived more intrinsically motivated were more willing to experiment and explore their fields of study. In a study conducted by Tardy and Snyder (2004), teachers who were intrinsically motivated by a strong connection and a sense of accomplishment in their English lessons, demonstrated a greater desire to teach in order to feel the same kind of success.

\section{Research Methodology}

The present research aims to investigate EFL teachers' reasons of choosing this job, to find out the most important sources of teacher motivation. The research incorporates methods of both qualitative and quantitative studies. The findings are backed up by self-observations of the author as an EFL teacher himself. Moreover, observations made during years of educating L2 learners, namely, of the dynamics of transformation, maintenance and fluctuation of motivation among colleagues is retrieved to further confirm the results of the study. The population of the study is English language teachers who are mostly from Turkey and who work in Fezalar Educational Institution (FEI). This educational institution consists of secondary schools, high schools and a university in different cities of Iraq. A 
description of participants, the instruments of the study and data collection methods and its analysis are presented below.

\subsection{Participants}

The participants consist of 37 English language teachers who were chosen randomly from the various schools of FEI. The respondents of this study are mainly from the high schools which makes $40.5 \%$, however, the other $32.4 \%$ are university lecturers which is the second largest group, and the other $27 \%$ of them are secondary school teachers. This study involves $69.9 \%$ (no.24) male and 35.1 (no.13) female teachers. For the age of the respondents, $8.1 \%$ (no.3) of them are below 25, 56.8\% (no.21) of them are between 26-30 years old which is the majority of the respondents, the other 29.1\% (no.11) are between the age of 31-40 and finally the other 5.4\% (no.2) of them are over 41 years old. Among the teachers who participated in this study, 40,5\% of them have been working as teachers of English between 6 to 10 years, $35,1 \%$ of them have less than 5 years of teaching experience, $21,6 \%$ have been teaching between 11 to 20 years and only $2,7 \%$ have over 21 years teaching experience. In terms of qualification, more than half of the participants $(51,4 \%$, ) have a BA degree, the other 40,5\% have Master's Degree and only the $8,1 \%$ of them are PhDs.

\subsection{Instrument and data collection}

The research instrument titled "Teachers' job Satisfaction and Motivation Questionnaire" (TEJOSAMOQ) was adapted for this study. A questionnaire consisting of close-ended and open-ended questions was developed and later tested with a small number of teachers. Moreover, the instrument was checked by several experts to prove its content validity. Then it was sent to 40 teachers by email. We received completed questionnaires from 37 of them, the resr refused to contribute. The questionnaire consisted of three parts. In the first part biographical information was obtained, for example: gender, age, teaching experience and the establishment they teach English at. The second part of the questionaire contained statements with yes/no answers to elicit answers to reaserch question one. We asked respondents to give the reasons that motivated them to choose teaching as a career since we think that there is a close relationship between the reasons behind opting for this job and their current job motivation. In the third part, we asked questions related to their current level of motivation. This part contained questions mainly on extrinsic motivating factors such as salary, feedbacks from supervisors, professional development opportunities, etc. In the fourth part, we tried to elicit respondents' attitutes towards the intrinsic factors that keep them motivated and this part was measured on a five point scale, from 1 strongly disagree to 5 strongly agree. In this part we tried to investigate which intrinsic factors mostly motivate teachers of English in FEI. For the statistical analysis of the data we used the statistical package for the social sciences (SPSS) 22 program.

\section{Data Analysis And Results}

Table 1. Reasons for choosing teaching as a career.

\begin{tabular}{lc}
\hline Social status of teacher & $55.1 \%$ \\
\hline Teaching fitting my lifestyle & $67.6 \%$ \\
Job security & $32.4 \%$ \\
Autonomy in the class & $32.4 \%$ \\
Summers off & $29.7 \%$ \\
Being born to teach & $32,4 \%$ \\
Having being pressurized to select this job & $21,6 \%$ \\
Not having got the desired admission & $18,9 \%$ \\
Potential of changing students' lives & $70 \%$ \\
Contributing to society & $65,5 \%$ \\
\hline
\end{tabular}

In the second part of the questionnaire we tried to investigate teachers' reasons for choosing this career. It can be seen from Table 1 that most teachers of FEI prefered this career due to altuiristic motives such as potential of changing students' lives (70\%), contributing society (65\%), thinking to be born to teach $(32 \%)$. However, there are other factors which had an effect on choosing this job. Among the respondents $67,6 \%$ agreed that teaching fitted their lifestyles. $55,1 \%$ of teachers claimed that a social status of a teacher was another reason for entering this job, since teaching is still highly valued in this culture. $32,4 \%$ of respondents claimed that they entered this career because of job security. Since it's fairly certain to find jobs in most countries, there is even a chance of working in different cities or countries. $32,4 \%$ of teachers stated that having autonomy in the classroom was another reason why they opted for this job. Once a teacher closes the classroom door behind he/she decides what to do. Not many jobs might guarantee this sort of autonomy. $29,7 \%$ of respondents agreed that summers-off were another reason for choosing this career, since summers-off might 
provide teachers with other jobs in summer or several months to relax. $21,6 \%$ of respondents agreed they were pressurized to select this job, while 18,9\% agreed they didn't get the admission they wanted, which are the least powerful motivators we found out in this study.

In the third part of the questionnaire we tried to investigate teachers' general level of current job satisfaction with different variables such as their perception of the salary, relationship with administrations, etc. It reveals that teachers in FEI are mostly satisfied with the salary, relationship with the administration and holidays /educational leaves. The results are presented in the tables and analysed using frequency and percentage principles.

Table 2. Are you generally satisfied with your job as a teacher?

\begin{tabular}{|c|c|c|c|c|c|}
\hline & & Frequency & Percent & Valid Percent & Cumulative Percent \\
\hline \multirow[t]{3}{*}{ Valid } & yes & 31 & 83,8 & 83,8 & 83,8 \\
\hline & no & 6 & 16,2 & 16,2 & 100,0 \\
\hline & Total & 37 & 100,0 & 100,0 & \\
\hline
\end{tabular}

The majority $(83,8 \%)$ of English language teachers in FEI agreed that they are satisfied with their job, only 16,2\% (no.6) stated that they are not satisfied.

Table 3. Do you have a reasonable salary?

\begin{tabular}{llrrrr}
\hline & \multicolumn{2}{c}{ Frequency } & \multicolumn{2}{c}{ Percent } & \multicolumn{2}{c}{ Valid Percent } & \multicolumn{2}{c}{ Cumulative Percent } \\
\hline Valid & yes & 31 & 83,8 & 83,8 & 83,8 \\
& no & 6 & 16,2 & 16,2 & 100,0 \\
& Total & 37 & 100,0 & 100,0 & \\
\hline
\end{tabular}

Table 3 shows that $83,8 \%$ (31) of teachers claimed that they receive a reasonable salary. It can be explained that FEI is a private educational institution and it pays well enough to the employees. Thus, most of them are satisfied. Table 2 and Table 3 reveal that the percentage of the teachers who agreed they are satisfied with the job and who agreed that they receive reasonable salary is the same $-83,8 \%$. This indicates that there is some correlation between the salary and job satisfaction in FEI; however, it doesn't necessarily mean a reasonable salary leads to job satisfaction. On the other hand, many other studies proved that a low salary might be a cause of job dissatisfaction.

Table 4. Do you think that you have good relationship with your administrators or supervisors?

\begin{tabular}{llrrrr}
\hline & Frequency & \multicolumn{2}{c}{ Percent } & Valid Percent & Cumulative Percent \\
\hline Valid & yes & 30 & 81,1 & 81,1 & 81,1 \\
& no & 7 & 18,9 & 18,9 & 100,0 \\
& Total & 37 & 100,0 & 100,0 & \\
\hline
\end{tabular}

In Table 4 it can be seen that $81,1 \%(30)$ of respondents agreed that they have a good rapport with their administration while $18,9 \%$ (no.7) of them didn't think similarly. During our interviews we recorded that many teachers stated that administrative factors help them get motivated. They noted that whenever they are asked to participate in the decision making process, it gives teachers an increased sense of belonging to the institution which consequently results in a better job performance and higher motivation. They also noted that when their administrators or supervisors celebrate important events or their achievements or celebrate the end of a busy week with food or beverages, it creates a positive climate which affects teachers' motivation as well.

Table 5. Holidays-Educational leaves?

\begin{tabular}{llrrrr}
\hline & Frequency & Percent & Valid Percent & Cumulative Percent \\
\hline Valid & yes & 28 & 75,7 & 75,7 & 75,7 \\
& no & 9 & 24,3 & 24,3 & 100,0 \\
& Total & 37 & 100,0 & 100,0 & \\
\hline
\end{tabular}


Table 5 demonstrates that $75,7 \%$ of teachers are satisfied with the holidays and educational leaves provided by FEI, while only $24,3 \%$ of them expressed their dissatisfaction.

In the fourth part of our questionnaire we investigated teachers' attitutes towards the intrinsic and exrtinsic factors that keep them motivated in FEI. The factors which are directly related to this study are measured on a five point scale, from 1 strongly disagree to 5 strongly agree and given in the table 6 .

Table 6. Source of motivation for FEI teacher. Descriptive Statistics

\begin{tabular}{|c|c|c|c|c|c|}
\hline & $\mathrm{N}$ & Minimum & Maximum & Mean & Std. Deviation \\
\hline $\begin{array}{l}\text { Having good relationship } \\
\text { with students }\end{array}$ & 37 & 1,00 & 5,00 & 4,5135 & ,76817 \\
\hline $\begin{array}{l}\text { My students' success in } \\
\text { language learning }\end{array}$ & 37 & 1,00 & 5,00 & 4,4595 & ,76720 \\
\hline $\begin{array}{l}\text { Sense of Achievement or } \\
\text { success }\end{array}$ & 37 & 1,00 & 5,00 & 4,3243 & ,78365 \\
\hline $\begin{array}{l}\text { Possibility of improving my } \\
\text { professional skills }\end{array}$ & 37 & 1,00 & 5,00 & 4,2432 & 1,01120 \\
\hline My work itself & 37 & 2,00 & 5,00 & 3,7297 & ,73214 \\
\hline Working conditions & 37 & 1,00 & 5,00 & 3,6757 & 91451 \\
\hline authotity and independence & 37 & 2,00 & 5,00 & 3,5946 & 68554 \\
\hline $\begin{array}{l}\text { Receiving praise from } \\
\text { administration, parents, } \\
\text { students }\end{array}$ & 37 & 1,00 & 5,00 & 3,4595 & 1,06965 \\
\hline Relationship with colleagues & 37 & 2,00 & 5,00 & 3,3514 & ,71555 \\
\hline fringe benefits & 37 & 1,00 & 5,00 & 3,3514 & ,82382 \\
\hline Valid N (listwise) & 37 & & & & \\
\hline
\end{tabular}

Scale: $1=$ Strongly disagree, $2=$ disagree, $3=$ neither agree or disagree, $4=$ agree, $5=$ strongly disagree

To ascertain mean values the collected data was analyzed by using a descriptive statistic method and the results revealed that the most important motivational factor for teachers of FEI is "having good relationship with students" which has a mean of 4,51 with SD 0.7, while "my students' language learning success" scored second with the mean 4,45 with SD 0.7 which is very close to the first one. The sense of achievement or success and the possibility of improving professional skills took the $3 \mathrm{rd}$ and 4 th position respectively with the mean of 4,32 and 4.24. These mean values prove that training programs for professional developments are one of the most important motivational factors that raise teachers' performance. "My work itself and working conditions" had means of 3,7 and 3,6. Authority and independence obtained the mean of 3,59, while receiving praise from administration, parents and students obtained the mean of 3,34. Relationship with collegues and fringe benefits are seen as the least significant sources for motivation in the list with the mean of 3,35 each. The above results demonstrate that most teachers in FEI agreed that mostly intrinsic factors motivate them.

\section{Discussion And Conclusion}

A motivated teacher is a key factor that importantly affects students' success in the educational process and helshe guides and shapes their worldview. Thus, motivation of teachers is highly important since it directly influences the learning process. Moreover, it maintains the interest of students to the course. Whatever degree of motivation a teacher brings to the classroom is transformed for better or for worse. A motivated teacher will work harder, try new approaches and do a lot for the sake of students which will in turn contribute to effective learning. Moreover, a motivated teacher will strive for the excellence and growth of the institution. Motivating teachers is one of the primary challenges for many school administrators because teacher motivation determines the level of success or failure in achieving an institution's goal in the educational process.

This study aimed to explore two main questions. First, what motivated English teachers at FEI to choose this career and second, to find out to which level FEI teachers are satisfied and to investigate their attitutes towards the intrinsic and exrtinsic factors that keep them motivated in FEI.

It has been a common question in teacher motivation researches to pinpoint the causes of opting for the teaching profession as the reasons behind entering it have a significant influence on educators' commitment to the job. The literature on teacher motivation demonstrates that new teachers' willingness to enter this job can be defined by intrinsic, extrinsic and altruistic factors. The results obtained in this study also demonstrate that there are intrinsic, extrinsic and altruistic factors that motivated teachers to enter this job. However, the most important reasons found in this study are intrinsic and altruistic factors that significantly motivated FEI teachers to make such a decision. These findings are in consonance with Wadsworth, (2001) in a research involving 914 public and private school teachers in the USA, she reports that $96 \%$ of them joined this profession due to intrinsic reasons. There are studies conducted by Muller et al. (2008), Dinham S. and Scott C. (2000), Kyriacou C and Coulthard M. (2000) and Hettiarachchi, (2010) which strongly support the findings of this study. In this study, among the intrinsic and altruistic reasons: teaching as an indispensible 
part of my life $(67.6 \%)$, potential of changing students' lives $(70 \%)$, contributing to society $(65.5 \%)$, ranked as the most important motivating key factors. These findings are in agreement with Frase (1992), who claims that people decide to become teachers to help young people learn and their most gratifying reward is accomplishing this goal. It indicates that teachers chose this job on the basis of intrinsic and altruistic reasons and they volunteered in teaching profession because of these reasons. Although many studies conducted by different researchers in different cultures disclose that the most common motivators are intrinsic reasons (Wadsworth, 2001, Watt H. M. G. and Richardson P. W., 2008), it might not be true to the same extend in all contexts. The survey also revealed that some of the participants had extrinsic and other reasons to select the teaching profession. The reasons mostly include other factors such as: a social status of a teacher, job security, autonomy in the classroom, summers-off and a profession suitable for women. Among these reasons, the most common was the social status of a teacher since it was stated by $55.1 \%$ of the participants. Job security (32.4\%) is another motive that drives teachers to enter this job since it's fairly certain to find teachers' jobs in some countries. Another extrinsic reason is "summers-off" $(32.4 \%)$ because not many jobs might provide several months to relax. We can see similar findings in the study conducted by Bastick (2000), where she studied teacher motivation in Jamaica and she detected that extrinsic reasons such as: the job with the most holidays, job security, opportunity for earning extra money, and a social status for teachers were among the factors which motivated teachers to join this profession. As this study revealed the teachers, who had not entered this profession because of intrinsic or altruistic reasons, had other drives in their lives for selecting teaching. They either could not reach other professional goals or somebody recommended teaching as a better choice. The study revealed that some teachers entered this profession because they were urged to do so by their parents. During the interview one female teacher mentioned how she had been pressurized by her parents to choose this job. This confirms that in some cultures a teaching profession is considered to be the best job for women. Some other teachers also stated that they didn't get the admission they wanted, so they resorted to teaching. One teacher mentioned that he wanted to study law but he didn't get the adequate points in the national test so he picked teaching. The explanation is that in some countries like Turkey, Iraq, etc. graduates with the lowest grades are admitted to colleges of education. Thus, the declining status of teachers can be a de-motivator for many new teachers in such cultures.

The second main question of this study was to find out to which level FEI teachers are satisfied and to investigate their attitutes towards the intrinsic and exrtinsic factors that keep them motivated in FEI. The study reveals that the majority of teachers in FEI seem generally satisfied with various aspects of their job such as the job itself, the salary and the relationship with the administrators. However, some teachers express their dissatisfaction with the relationship they have with their administrators which is considered a dissatisfying source for teacher motivation. This study implies that there is some interdependence between the salary and job satisfaction in FEI, however, it doesn't necessarily mean a reasonable salary leads to job satisfaction. On the other hand, many other studies indicated that a low salary might be a cause of job dissatisfaction. Similar results (Evans 1998, Maenpaa 2005) were also found in other researches. Evans (1998) found that many teachers wanted to leave their jobs as a result of low salary. Doyle G and Kim Y. M. (1999) carried out a research on teacher motivation and found that salary, teacher-administrator relationship, curriculum, course materials, heavy workload, lack of job security and autonomy were the causes of teachers' demotivation. Another study conducted by Connie (2000) demonstrated similar results. In her research involving 98 Mexican English teachers, she found that demotivating factors included a low salary, the lack of teaching materials, an inflexible curriculum, a heavy workload and the lack of enthusiasm in teaching. However, in a recent study Hettiarachchi (2010) found that poor relationship among colleagues and teacher transfer were among the highest-rated demotivating factors. All these studies support our finding by stating that salary and the relationship with administrators, supervisors or colleagues might be the causes of job dissatisfaction which will in turn lead to low motivation.

In terms of motivating factors, most teachers agreed that primarily intrinsic factors motivate them. Teachers value having good relationships with the students and it is the most important motivator while the students' language learning success is the second important drive. Positive relationships with students will certianly lead teachers to better deal with students' problems or needs which will in turn lead to improved teacher motivation. Similiar findings were also discovered by Colodarci (1992). These findings also agree with Tardy and Snyder (2004) who found that teachers who were intrinsically motivated by a strong connection and a sense of accomplishement in their English lessons, demonstrated a greater desire to teach in order to feel the same kind of success. Dinham S. and Scott C. (2000) obtained similar results, in their study when they discovered students' academic achievements as being one of the common motivators for teachers among others. Moreover, most teachers feel motivated when their students achieve success and when they perform desired tasks successfully. Another study that supports these findings was conducted by Connie (2000) involving Maxican EFL teachers, she found that the most important factors that motivate teachers are better performance among students and students' own motivation. This study makes evident that the realtionship between teachers and students is a crucial source of motivation or de-motivation. Students' lack of commitment to the subject might also make teachers feel burnout, demotivated or stressed. Thus, students' willingless to learn is one of the most important factors for teacher motivation. Vanderberge and Hubberman (1999) also confirmed the importance of student- teacher relationship as an enhancing factor for teacher job satisfaction. Additionally, Barnaus M., Wilson A. and Gardner R. C. (2009) analyzed the relationship between the teachers' and students' motivation and its influence on students' accomplishements. They found that the close interconnection between them facilitated students' achievements. The findings of this study revealed that, regardless of culture in which teachers teach, most of them obtain their motivation both from teaching itself and from their students. 
Possibility of improving professional skills is another motivating factor found in this study. It is suggested that training programs are one of the most important motivational aspects that boost teachers' performance. This finding is in consonance with Woodward (1992) who considered the training as a motivational force and with Qayyum A. and Siddique M. (2003) who found in their research that teacher's competency motivated them to perform well. Dinham S. and Scott C. (2000) also found that self-growth opportunities and mastery of professional skills were among the common motivators for teachers. However, participants of this study, in particular, of the interviews, were unhappy with the lack of opportunities available for their professional development. They complained about having limited possibilities for professional development in FEI. This is a common finding in teacher motivation study that teachers often lose their motivation if they are not provided with the opportunity of professional development.

The study also suggests that many teachers feel motivated when their efforts are fairly recognized and praised by the administration, parents and students. This finding supports the Expectancy Theory. Individuals will respond favorably if they perceive their goals are realistic, achievable and a reward comes with them. teachers are known to be more motivated when their efforts are rewarded and they are not sufficiently productive if their attempts are not equally compensated. Thus, teachers are more likely to be motivated if their goals seem achievable and a particular "prize" is expected. We also believe that teachers should be provided with feedbacks to realize their weaknesses and strengths and positive efforts should be rewarded by the administration. If sufficient feedback is not given about the task performed by teachers, it might affect teacher's performance negatively because teachers should be aware of the results of any task implemented in the classroom (Mufflin, 1995).

Although most of the findings are in agreement with the results of teacher motivation research in other countries, the results of this survey about the teacher pay demonstrated different findings. In most studies conducted in different countries incentive pays and fringe benefits were among the primary de-motivators for teachers (VSO, 2002). However, in this study the majority of teachers don't regard fringe benefits and incentive pay in this way which is in agreement with Odden and Kelley (1997) who reviewed various researches and experiences concluded that individual merit and incentive pay programs do not work and, in fact, are often detrimental. Thus, fringe benefits and merit pay programs are not suitable for schools and universities where teachers are supposed to work cooperatively and in harmony. The study, conducted by Ramachnadran et al. (2005) in India, revealed similar results about concerning teacher salary, where teachers mentioned their contentment with the salary. Other teacher motivation studies have demosntrated as well that the amount of salary does not play a significant role in teacher motivation. The findings of this study confirm that a salary doesn't seem to be as significant as many beleive. This could be primarily because, teachers in a private sector a receive reasonable salary. The results of this study also demonstrate that working conditions might impinge on teacher motivation and satisfaction. In teacher motivation research, the studies revealed that physical conditions of classrooms, insufficient teaching materials and heavy workloads might be the utmost source of demotivation and they are likely to negatively affect teacher commitment.

Teacher motivation is also concerned with job satisfaction. It is important to keep teachers' intrinsic motivation high, since the higher intrinsic motivation educators have the more satisfied they will be with their work (Davis J. and Wilson S. M., 2000). We believe that a motivated teacher can certainly have a significant influence on students' perception and desire to learn. It is experienced that students whose teachers are highly motivated seem to be more engaged in the learning process. Positive interaction and rapport with learners lead teachers to better work with their students' needs individually, and thereby create teacher efficacy and improve teacher motivation (Colladarci, 1992). Most teachers feel motivated when their students are able to achieve success or when they perform desired tasks successfully. Since motivation is contextual and it can be influenced by administrative, social, economic and personal issues, the school/ university administrators must find ways to deal with teachers' low motivation. In order to raise the motivation of a teacher they should carefully distinguish between the intrinsic and extrinsic rewards as well.

\section{References}

Barnaus M., Wilson A. and Gardner R. C. (2009). Teachers' motivation, classroom strategy use, students' motivation and second language achievement. Porta Linguarum, 12, 25-36.

Bastick, T. (2000, February). The measurement of teacher motivation: Cross-cultural and gender comparisons. Paper presented at the annual meeting of the Society for Cross-Cultural Research. New Orleans, LA.

Colladarci, T. (1992). Teachers' sense of efficacyand commitment to teaching. Journal of Experimental Education, 60, 323-337.

Connie, R. J. (2000). Factors influencing motivation and de-motivation of Mexican EFL techers . Paper presented at the annual meeting of Teachers of English to Speakers of Other Languages. Vancouver, Canada: Retrieved from the ERIC database. (ED459605).

Davis J. and Wilson S. M. (2000). Principals efforts to empower teachers: Effects on teacher motivation and job satisfaction and stress. The Clearing House, 73(6), 323-349.

Dessler, G. (2001). Management: Leading People and Organization in the 21st Century. Harlow: Prentice Hall.

Dinham S. and Scott C. (2000). Moving into the third, outer domain of teacher satisfaction. Journal of Educational Administration, 38(4), 379-396.

Dörnyei, Z. (2001). Teaching an Researching Motivation. Harlow, England: Longman. 
Dörnyei, Z. (2003). Attitudes, orientations and motivations in language learning. Advance in theory, research and applications, 53(1), 3-31.

Doyle G and Kim Y. M. . (1999). Teacher Motivation and Satisfaction in the United States and Korea. MEXTESOL Journal, 23, 35-48.

Evans, L. (1998). Teacher Morale, Job Satisfaction and Motivation. London: Chapman Paul Publishing Limited.

Frase, Larry E. (1992). Maximazing people power in schools: Motivation and managing teachers and staff. Newbury Park, CA: Corwin Press, Inc.

Gibson, James L., Ivanchevich, John M. and Jr. James H. (2000). Organization-Bahaviour- Structure-Process. 10th Edition. Boston: McGraw-Hill.

Golombiewski, R. (1973). Motivation in Carl Heyel (Ed), The Encyclopedia of Management 2nd. New York: Vam Nostrand Reinhold.

Harmer, J. (2001). The Practice of English Language Teaching. Essex: Longman Press.

Herzberg F., Mausner B., Snyderman B. B. (1959). The Motivation of Works (2nd ed.). New York: John Wiley an Sons.

Hettiarachchi, S. (2010). ESL teacher motivation in Sri Lankan public schools. Masters Theses and Doctoral Dissertations.

Ifinedo, P. (2003). Employee motivation and job satisfaction in Finnish organiation: Astudy of employee in the Oulu Region, Finland. Master of Business Administration thesis. London: University of London.

Johnson, C. R. (2001). Factors influencing the motivation and de-motivation in Mexican EFL teachers. MEXTESOL Journal, ERIC Document Reproduction Service No. 459605.

Johnson, Susan Moore. (1986). Incentives for Teachers: What motivates, What Matters. Educational administration Quarterly, 22(2), 54-79.

Kyriacou C and Coulthard M. (2000). Undergraduates' views of teaching as a career choice. Journal of Education for Teaching, 34(4), 117-126.

Lawler, E. E. (1993). "Merit Pay: An Obsolete Policy?" in Perspectives on Behavior in Organization. (L. W. Porter, J. R. Jackman , \& L. W. Porter, Eds.) New York: McGraw-Hill.

Maslow, A. H. (1943). A Theory of Human Motivation. Psychological Review, 50, 370-396.

Odden A. R., Kelley C. J. (1997). Paying teachers for what they know and can do: New and smarter compensation strategies to improve schools. Thousand Oaks, CA: Corwin Press.

Pennington M. C. and Ho B. (1995). Do ESL educators suffer burnout? Prospect(10), 41-53.

Pennington, M. C. (1991). Work satisfaction and the ESL profession. Language, Culture and Curriculum, 4(1), 59-86.

Pennington, M. C. (1992). Motivating English language teachers through job enrichment. Language, Culture and Curriculum, 5, 199-218.

Pennington, M. C. (1995). Work satisfaction, motivation and commitment in teaching English as a second language. New York: ERIC Cleaering house (ERIC no ED404850).

Qayyum A. and Siddique M. (2003). Let's Enhance the Performance of the Teachers: A study of Motivational Techniques used by School heads. Journal of Elementary Education, 13, 21-28.

Rosenfelf R. H., Wilson D. C. (1999). Managing organization: Text, Rading and Cases. London: McGraw Hill.

Schultz H., Bagraim J., Potgieter T., Viedge C. and Werner A. (2003). Organizational Behaviour: A contemporary South African Perspective. Pretoria: Van Schaik Publisher.

Sergiovanni, T. (1967). Factors which affect satisfaction and dissatisfaction of teachers. Journal of Educational Administration, 5, 66-81.

Tardy C. M.and Snyder B. (2004). "That's why I do" flow and EFL teachers practices. ELT Journal, 58, 118-128.

Vanderberghe R., Huberman A. M. (1999). Understanding and Preventing Teacher Burnout. Cambridge: Cambridge University Press.

Wadsworth, D. (2001). Why new teachers choose to teach? Educational Leadership, 58(8), 24-28.

Watt H. M. G. and Richardson P. W. (2008). Motivations, perceptions, and aspirations concerning teaching as a career for different types of beginning teachers. Learning and Instruction, 18, 408-428.

Wild T. C., Enzle M. E. and Hawkins W. L. (1992). Effects of perceived extrinsic versus intrinsic teacher motivation on student reactions to skill acquisition. Personality and Social Psychology Bulletin, 18, 245-251. 